\title{
METODOLOGÍA PARA LA NARRATIVA DE TRADUCCIONES CENSURADAS INGLÉS-ESPAÑOL. ANÁLISIS DEL CORPUS 0 TRACEni
}

(1962-1969)

\author{
MARTA RIOJA BARROCAL \\ Universidad de León
}

\section{Resumen}

Este trabajo pretende cumplir dos objetivos; primeramente describir la metodología adecuada para desarrollar un trabajo descriptivo utilizando los corpus textuales como herramienta de trabajo, a la par que poner de manifiesto los resultados más relevantes obtenidos de un análisis estadístico del Corpus 0 TRACEni (1962-1969), constituido por textos narrativos condicionados por la censura franquista. Para su consecución se tienen presente los Estudios Descriptivos de Traducción, sin perder de vista en un futuro próximo la transición metodológica de construcción de los Corpus 1 y 2, que permitirán obtener datos fiables para llegar al establecimiento de regularidades en el comportamiento traductor. Será entonces el momento de formular normas válidas en este campo de estudio tan interdisciplinar.

Palabras clave: TRACE (traducción y censura), Estudios Descriptivos de Traducción (EDT), textos narrativos, regularidades traductoras.

\begin{abstract}
This paper aims to fulfil two main objectives; firstly the description of a suitable methodology to develop a descriptive study using textual corpora as a tool, as well as giving account of the most relevant results obtained from a statistical analysis of Corpus 0 TRACEni (1962-1969), consisting of narrative texts under the censorship constraint. Descriptive Translation Studies remain at the background. In the near future the methodological transition of Corpus 1 and 2 is in mind. The consequent empirical data will allow us to establish regularities in the translating behaviour and it will be the time to formulate valid norms for this interdisciplinary field of study.
\end{abstract}

Key words: TRACE (ranslation and censorship), Descriptive Translation Studies (DTS), narrative texts, translation regularities. 


\section{[1. El estudio descriptivo de la censura en traducción. Metodología}

n estas líneas pretendemos desarrollar la metodología seguida en
nuestro estudio basándonos en los presupuestos fundamentales de la disciplina teórica por la que hemos apostado como eje de nuestras pesquisas: los Estudios de Traducción (ET), y más concretamente los Estudios Descriptivos de Traducción (EDT) con la ayuda de corpus textuales, ya que pretendemos «(1) to describe the phenomena of translating and translation(s) as they manifest themselves in the world of our experience, and (2) to establish general principles by means of which these phenomena can be explained and predicted $»^{1}$. Los EDT son el puente entre la teoría y la práctica, ya que además de ser la piedra angular sobre la que se construye toda teoría, son el punto de partida de las aplicaciones a la traducción puesto que toman como base los datos empíricos. El estudio que aquí se describe, y que servirá como propuesta para llevar a cabo cualquier trabajo de corte descriptivo, partirá, por tanto, de los hechos observables, más concretamente de textos narrativos escritos en inglés y sus correspondientes traducciones al castellano en el periodo 1962-1969. No podemos olvidar que en este periodo tan controvertido cualquier manifestación artística, independientemente del medio en el que se produjera, se vio afectada por el condicionamiento de la censura.

En este momento conviene puntualizar que el trabajo hasta ahora realizado se enmarca dentro del proyecto TRACE (TRAducciones CEnsuradas). El objetivo prioritario de este equipo de investigación a lo largo de la última década es, como afirma la Doctora Rabadán de la Universidad de León, «desentrañar los mapas de las prácticas traductoras en España, su interacción

\footnotetext{
${ }^{1}$ J.S. Holmes, Translated! Essays on Papers on Translation Studies, Amsterdam, Rodopi, 1988a, pp. 71.
} 
con factores extratextuales, su plasmación lingüística y textual y las posibles consecuencias de dichas prácticas sobre otros modos de traducir» ${ }^{2}$. La investigación TRACE ${ }^{3}$ se encuentra subdividida en tres ámbitos genéricos ${ }^{4}$. Nuestro objetivo particular en última instancia, mediante la aportación de datos empíricos y conclusiones fiables obtenidas por medio de un trabajo descriptivo, pretende ampliar las nociones preconcebidas sobre la problemática censora en el campo de la narrativa, en una época concreta dentro del franquismo 19621969. Por eso, como parte integrante del proyecto TRACE, pretendemos establecer las bases necesarias para proceder al posterior análisis de las prácticas traductoras al castellano de textos narrativos cuya lengua origen sea el inglés, durante el periodo concreto anteriormente mencionado. Analizando las traducciones de dichos textos narrativos pretendemos llegar en un futuro no lejano al establecimiento de regularidades en el comportamiento traductor de los productos importados, traducidos y censurados en dicha época. La posibilidad de encontrar regularidades que se puedan aplicar a los datos empíricos y a las teorías es uno de los principales objetivos de los EDT.

Dentro del marco teórico en el que encuadramos nuestro proyecto, es decir, los EDT, hemos utilizado tres propuestas que abogan por una metodología descriptiva que explique y dé cuenta de los datos empíricos encontrados. Estas propuestas son la de Toury ${ }^{5}$, considerado el padre de los

\footnotetext{
2 R. Rabadán, (ed). Traducción y censura inglés-español: 1939-1985. Estudio Preliminar, León, Universidad de León, ULE, 2000a, pp. 9.

${ }^{3}$ Este proyecto es el resultado de trabajos de investigación realizados dentro del campo de los Estudios de Traducción en las Universidades de León y del País Vasco.

${ }^{4}$ Los ámbitos que abarca la investigación TRACE son: traducción y censura de textos narrativos (TRACEn) (Rabadán 2000a, Pérez Álvarez 2002, Gómez Castro 2004, Rioja Barrocal 2004), teatrales (TRACEt) (Merino 1994, Pérez de Heredia 2003) y audiovisuales (cine: TRACEc y televisión: TRACEtv) (Gutiérrez Lanza 2000a, Serrano 2003).

5 G. Toury, Descriptive Translation Studies and Beyond, Ámsterdam/Philadelphia, John Benjamins, 1995.
} 
EDT, Tymozcko ${ }^{6}$, que ha reutilizado el método descriptivo en la traducción de cuentos heroicos irlandeses al inglés, y Gutiérrez Lanza7, que se ha servido de este método incorporando el uso de un Corpus 0, un Corpus 1 y un Corpus 2 a la descripción de la censura cinematográfica en Traducción.

Dado que los EDT resaltan la importancia de la cultura meta eso sí, sin por ello desprestigiar la origen, consideramos que abordar el contexto históricocultural de la cultura meta en el periodo delimitado es de obligado cumplimiento. El aspecto cultural influye de forma determinante en el trabajo del traductor, que en muchas ocasiones se ve obligado a adaptar el texto origen a la cultura meta para que el texto sea aceptable. Como afirma Toury: «Translation activities should rather be regarded as having cultural significance» ${ }^{8}$.

El estudio de la recepción de textos narrativos en España durante el periodo franquista se halla irremediablemente ligado a las diferentes etapas políticas en las que dicho periodo se puede subdividir. La acotación del periodo delimitado entre 1962 y 1969 se debe a la intención de analizar los datos empíricos que se produjeron en este periodo de gobierno aparentemente "más aperturista", en el que cabe destacar la figura de Manuel Fraga Iribarne a la

${ }^{6}$ M. Tymozcko, «Connecting The Two Infinite Orders. Research Methods In Translation Studies», en T. Hermans (ed), Crosscultural Transgressions. Research Models in Translation Studies II. Historical and Ideological Issues, Manchester, St. Jerome, 2002, pp. 9-25.

${ }^{7}$ C. Gutiérrez Lanza, 2004b, «Herramientas de investigación de EDTAV: la Ficha y el Catálogo TRACEc», en Ortega Arjonilla, E. (dir). Panorama actual de la investigación en Traducción e Interpretación. Vol III. Granada: Atrio, 447-455. Siguiendo su método, recordamos el proceso a seguir desde la construcción del Corpus 0/Catálogo hasta la elaboración de un Corpus 2:

1- Catálogo/Corpus 0: análisis cuantitativo y cualitativo de los registros incluidos en el Corpus 0.

2- Corpus paralelo 1, constituido por uno o varios subcorpus (1a) de textos en inglés y los correspondientes subcorpus (1b) de textos de las traducciones de los originales.

3- Corpus 2, constituido por las unidades bitextuales seleccionadas en ambas lenguas sobre las que se realizará el análisis comparativo-descriptivo. Aquí también es posible tener un subcorpus (2a), de las unidades escogidas en inglés, y un subcorpus (2b), de las traducciones de esas unidades originales.

8 G. Toury, op. cit., p. 53. 
cabeza del Ministerio de Información y Turismo, ministerio del que dependían directamente las Comisiones de Censura que se aplicaban a los textos narrativos. En este sentido, la selección de nuestro espacio temporal (1962-1969) no es aleatoria sino que además de querer completar esta época con Fraga al mando de los controles censores, se pretende seguir una continuidad con otros trabajos de investigación ya iniciados, que cubren la época anterior y posterior a la nuestra.

El contexto receptor donde las traducciones tienen lugar como producto es muy significativo. Por eso, el hecho de que cualquier estudio descriptivo esté orientado hacia el polo meta responde a la norma inicial que adopta el traductor; bien sea la de "adecuación", que consiste en acercarse al original manteniendo sus convenciones contextuales o, la de "aceptabilidad"9, que consiste en modificar el texto meta acercándolo lo más posible a la cultura meta. Al fin y al cabo, «la función prospectiva de una traducción rige inevitablemente las estrategias que se adoptan durante la producción del texto en lengua meta con la intención de aplicarlas, y rige, por extensión, todo el proceso de traducción en el que se incluyen tales estrategias» ${ }^{10}$. Por consiguiente, según el traductor haya planteado su proyecto de acuerdo con la norma inicial, «así se someterá a las normas de aceptabilidad impuestas por el polo meta o a las de adecuación impuestas por el polo origen» ${ }^{11}$. De ahí, que el contexto receptor en los ámbitos más relevantes de la vida social: el político, el económico y el cultural o cualquier otro condicionamiento externo, adquiera una importancia relevante para los EDT porque cualquiera de estos ámbitos pueden afectar a la

\footnotetext{
${ }^{9}$ R. Rabadán, Equivalencia y traducción, León, Universidad de León, 1991, pp. 54.

${ }^{10}$ G. Toury, "What Lies Beyond Descriptive Translation Studies?", en M.A. Vega \& R. MartinGaitero (eds.), La palabra vertida. Investigaciones en torno a la traducción. Actas de los VI Encuentros Complutenses en torno a la traducción, Madrid, Editorial Complutense, 1997, pp. 69-80. [Versión en español en http://www.tau.ac.il/ toury/].

${ }^{11}$ R. Rabadán, op. cit., p. 133.
} 
producción textual. En nuestro caso concreto no se debe perder de vista el funcionamiento de la (auto)censura, los criterios de control de la información ${ }^{12}$ y la Ley de Prensa de 1966. Es muy probable que todos estos factores extratexuales incidieran en la producción textual que llegaba a los lectores españoles de nuestra época. Centrándonos en el ambiente de la España franquista, absolutamente todo lo que se publicaba a través de cualquier medio de expresión, sin excepción, tenía que pasar por los trámites burocráticos de la censura. Precisamente, la "orientación bibliográfica del Secretariado", eufemismo para referirse a la censura, no examinaba la calidad literaria de la obra, sino que más bien pretendía dar unas pautas a seguir acerca del modo de escribir de acuerdo con el comportamiento moral. El gusto, en la mayoría de los casos, estaba estrechamente relacionado con las convicciones morales de los censores, por lo que limpieza, catolicidad y tradicionalismo se convertían en criterios también estéticos. Los criterios utilizados por los censores, y que a su vez estaban fundamentados en los postulados morales que regían el país, se pueden agrupar fundamentalmente en tres grandes bloques; morales, religiosos y políticos. En relación con el primer bloque, se prohibían los pasajes cargados de obscenidades, entre los que se cuenta toda clase de relaciones amorosas antiéticas o pasajes que iban desde la pura pornografía hasta las violaciones de la moral conyugal o situaciones y ambientes atrevidos. La prohibición de cuestiones relacionadas con la sexualidad se extendía, además, a las descripciones del cuerpo humano. En lo referente a los criterios religiosos, los ataques a la religión católica solían ser motivo de una condenación severa y era intolerable, igualmente, la descripción de religiones diferentes de la católica o la apología de cualquier forma de anticlericalismo. Con respecto a los criterios

${ }^{12}$ J. Sinova, La censura de Prensa durante el franquismo (1936-1951), Madrid, Espasa Calpe, 1989. 
políticos, se arremetía contra toda literatura ideológicamente hostil al franquismo, así como contra todas las obras que entrañaran peligros semejantes por referirse a conflictos sociales o a libros comunistas.

Teniendo en mente el contexto socio-político del franquismo con el atenuante del mecanismo censor en el que se desarrollaron las traducciones objeto de estudio, podemos plantearnos ciertas preguntas que podrán ser resueltas tras la culminación del análisis descriptivo. Por eso, un factor fundamental en la planificación de la investigación descriptiva dentro del marco teórico de los EDT es la formulación de hipótesis, que juegan un papel crucial en la investigación a través de la explicación y la descripción de fenómenos de traducción a gran escala, en los que el producto, la función y el proceso, interactúan. Algunas de las hipótesis que pretendemos verificar en un futuro próximo son las siguientes: ¿cuál es la posición del traductor en la cultura origen y en la cultura meta?, ¿qué normas de traducción adopta el traductor tipo de la época?, ¿es la autocensura una norma utilizada con frecuencia por los traductores de textos narrativos en España de 1962 a 1969?, ¿qué soluciones ha encontrado el traductor ante los problemas a los que se enfrenta?, ¿ha tenido incidencia la cultura origen y/o meta en la traducción como proceso y producto? o ¿existe una relación directa entre la autocensura del traductor (en caso de ser existente), sus hábitos profesionales y el funcionamiento de la censura externa que controlaba la producción textual?.

Procedemos ahora a explicitar brevemente la metodología utilizada para el desarrollo de cualquier estudio que utilice el método descriptivo, unificando las tres propuestas que ya habíamos mencionado con anterioridad y que han servido para desarrollar nuestro método de trabajo. Ya mencionamos que abogamos por el uso de los corpus lingüísticos informáticos como herramientas valiosas para desarrollar con eficacia un trabajo descriptivo, teniendo en cuenta 
las ventajas y aplicaciones de su uso en los EDT. Pero para llevar a cabo esta tarea de descripción y explicación de fenómenos, es necesario, en primer lugar, seguir el proceso de construcción y análisis del Corpus 0/Catálogo TRACEni (1962-1969) y posteriormente del Corpus 1 y 2 denominados de igual modo. La utilización de un corpus paralelo bilingüe que contenga textos narrativos originales en inglés y sus correspondientes traducciones al español es de suma importancia, porque supone una mediación entre el sistema teórico-conceptual del investigador y la realidad que se investiga. Los corpus, no obstante, no son absolutamente fiables, pero sí una herramienta de trabajo muy valiosa para el investigador, que será quien conociéndolo más en profundidad, haga buen uso final del mismo. Una posibilidad que ofrece el uso de corpus paralelos es alinear las unidades bi-textuales de los grupos textuales que se están comparando en los diferentes idiomas en los que están escritos los textos. El establecimiento previo de la unidad de alineación dependerá, en cualquier caso, de lo que se desee comparar.

El primer paso a seguir en la investigación descriptiva con la ayuda de corpus consiste en construir inicialmente un Corpus 0, para posteriormente ser capaces de analizar los datos de todos los registros que constituyen este Corpus 0 . Para ello es necesario establecer criterios $^{13}$ que posibiliten incluir o rechazar las entradas de registros en dicho Corpus. En el Corpus 0 se incluirán todos los textos narrativos que originalmente fueron escritos en inglés y posteriormente traducidos al castellano entre 1962-1969. La siguiente tarea en el proceso investigador, será llevar a cabo un análisis cualitativo y cuantitativo de los datos empíricos que figuran en el Corpus 0 para poder agrupar conjuntos textuales homogéneos que contengan ciertas similitudes y llegar a la

\footnotetext{
${ }^{13}$ En nuestro caso concreto estableceremos los criterios de registros válidos de nuestro Corpus 0 en el siguiente apartado.
} 
construcción del Corpus 1. Esta tarea será fundamental para reducir los límites de nuestro trabajo y poder realizar un estudio descriptivo-comparativo abarcable de un grupo de conjuntos textuales. Debido al interés de estudiar la narrativa importada y traducida en el periodo que nos atañe, y más concretamente, la narrativa en la que se refleja la actuación de la (auto)censura, se deberán de nuevo establecer criterios de selección que centren nuestra atención en este ámbito.

Seguidamente, una vez que se haya llegado a la construcción y análisis del Corpus 1, compuesto por textos completos en las lenguas con las que se esté trabajando, se debe proceder a la construcción del Corpus paralelo 2, formado por aquellas unidades bi-textuales que presenten interés para los objetivos de nuestra investigación. Ahora «es el momento de recordar cuáles son nuestras hipótesis de partida y localizar en el TO los fragmentos que pueden resultar problemáticos y los fragmentos correspondientes en el TM, donde se puede manifestar la posible incidencia de la (auto)censura (o viceversa)»14. En nuestro caso, el futuro Corpus 2 estará formado por aquellas unidades bi-textuales que reflejen todos los casos evidentes de la actuación de la censura externa en los textos traducidos, o bien de la autocensura o del umbral de permisividad (este término se corresponde con los ejemplos de unidades en las que la censura externa pasó por alto contenidos que en otros momentos sí censuraron por ser "perniciosos" para los lectores meta, siguiendo los criterios morales de la época, pero que en esos momentos los censores consideraron oportuno pasar por alto). Es en este momento de la investigación donde se podrá llevar a cabo el análisis comparativo propiamente dicho. Por eso, después de haber descrito las características del Corpus 0 y del Corpus 1, y cuando se cuente con el corpus

\footnotetext{
${ }^{14}$ C. Gutiérrez Lanza, «La labor del equipo TRACE: metodología descriptiva de la censura en traducción», en Merino, R.; J.M. Santamaría \& E. Pajares (eds), Trasvases Culturales: Literatura, Cine y Traducción 4, Vitoria, Servicio Editorial de la Universidad del País Vasco, 2005, pp. 59.
} 
Metodología para la narrativa de traducciones censuradas inglés-español...

paralelo de textos en inglés y sus traducciones en castellano, en última instancia, nuestra tarea será la de realizar un análisis descriptivo-comparativo, con el fin último de comprobar las normas ${ }^{15}$ traductoras y observar las soluciones adoptadas por los traductores ante el fenómeno de la censura externa, quizá, uno de los condicionamientos que mayormente afectó la producción textual de nuestra época. Para llevar a cabo esta labor y con la utilización de un corpus paralelo representativo de textos alineados, podremos observar cuáles han sido los cambios, si les ha habido, y también dar cuenta de las supresiones o modificaciones que se ejecutaron en las traducciones con respecto a los textos originales. Aparte de contar con el material textual, el uso de paratextos $^{16}$ como comentarios sobre obras, archivos y expedientes de censura, tachaduras del censor, órdenes de la editorial, etc., también son de gran utilidad. Finalmente, mediante la conclusión de un estudio descriptivo de esta envergadura, se podrán verificar las hipótesis de partida y observar qué sucedió con la narrativa importada y traducida en un periodo concreto del franquismo.

\section{[2. El Corpus 0/Catálogo TRACEni (1962-1969): Construcción y Análisis]}

Hasta este momento se han descrito los pasos necesarios para llevar a cabo un estudio descriptivo teniendo presente el marco teórico de los EDT. Para proseguir con la continuidad en la investigación descriptiva, ya señalamos con

\footnotetext{
${ }^{15}$ El concepto de normas es uno de los pilares fundamentales en los que se apoyan los EDT. Toury (1978: 53-54, 1995) y Rabadán (1991) lo han desarrollado en más profundidad.

16 Ver C. Alvstad, La traducción como mediación editorial. Un estudio de 150 libros para niños y jóvenes publicados en Argentina durante 1997, Doktorsavhandling, Göteborgs Universitet, 2003 y E. Genette, Paratexts. Thresholds of interpretation, Cambridge, CUP. Traducción de Jane E. Lewin del original francés de 1987: Paratextes, Paris, Senil, 1997.
} 
anterioridad que una etapa clave es la construcción y análisis del Corpus $0^{17}$. Precisamente nuestro segundo objetivo principal en este artículo pretende reflejar los resultados más relevantes obtenidos una vez construido y analizado nuestro particular Corpus 0/Catálogo TRACEni (1962-1969), denominado así por contener información necesaria para identificar los TOs y TMs narrativos escritos originalmente en inglés y traducidos al castellano en el periodo indicado. Para poner de manifiesto los datos que a continuación se aportarán, tenemos que hacer referencia a un anterior estudio cualitativo y cuantitativo previamente llevado a cabo ${ }^{18}$.

Inicialmente indicamos que para la construcción del Corpus 0 se ha hecho uso de las diversas fuentes con las que hemos contado para obtener la información. Fuentes tanto en soporte informático (Ariadna, REBECA, BPE, REBIUN, ISBN y del AGA) como las recogidas en catálogos publicados en antologías de la Biblioteca Nacional (Index Translationum, El Libro Español, Libros Nuevos y la Bibliografía Española). Seguidamente especificamos los criterios empleados para aceptar o rechazar toda la información de la que disponíamos. Entre los criterios de selección de registros válidos cabe mencionar el de tipo cronológico, el periodo meta seleccionado es de 1962 a 1969. b) En segundo lugar, aplicando el filtro de la tipología textual, sólo estaremos interesados en novelas o relatos cortos, quedando excluidas otras tipologías textuales como obras de teatro, comics, libros religiosos, políticos, etc. c) El tercer criterio es lingüístico. Nos centraremos en novelas escritas originalmente en inglés y

\footnotetext{
17 Por limitaciones puramente espaciales, en este segundo apartado de este artículo, nos centraremos exclusivamente en la construcción y análisis del Corpus 0 y reservaremos la construcción y análisis de los Corpus 1 y 2 respectivamente para artículos venideros.

${ }_{18}$ M. Rioja Barrocal, Traducción inglés-español y censura de textos narrativos: Construcción y Análisis del Corpus 0 TRACEni (1962-1969), León, Universidad de León. Memoria de Licenciatura inédita, 2004.
} 
traducidas al castellano, independientemente de la nacionalidad de los autores, que puede ser de muy diversa índole. Cuando obtuvimos de las fuentes de información empleadas todos los datos concernientes a cada uno de los registros que forman parte del Corpus 0 , se procedió a verter toda esta información en los campos que componen la Ficha modelo TRACEni (19621969), para así construir nuestro propio Catálogo.

Después, procedimos a realizar el análisis cuantitativo y cualitativo de los datos empíricos encontrados. Análisis que nos ha permitido establecer ciertos criterios de agrupación textual, teniendo presente la coordenada de homogeneidad 19 (por mismos autores, editoriales, calificación censora, etc.). Este análisis nos ha posibilitado la selección de grupos textuales para llegar al paso siguiente; conseguir una muestra representativa de los textos originales y traducidos que pasarán a formar parte de nuestro Corpus 1. A partir del análisis de los diversos campos analizados ha sido posible seleccionar una serie de grupos textuales homogéneos que contienen características similares y que pueden ser analizados en el futuro en la fase final descriptiva-comparativa. Ahora mencionaremos y expondremos las conclusiones más significativas de los campos analizados de entre los varios que configuran la ficha TRACEni: «Fecha publicación», «Autor Original», «Nacionalidad», «Autor Meta o Traductor», «Título Meta», «Lugar publicación», «Editorial», «Páginas TM»y «Calificación».

Aclaramos que hasta este momento nuestro Corpus 0/Catálogo TRACEni (1962-1969) contiene 9118 registros de textos narrativos escritos en inglés pero importados y traducidos al castellano durante 1962-1969. Sin

19 R. Caravedo, Lingüística del Corpus. Cuestiones teórico-metodológicas aplicadas al español. Colección Gramática Española. Enseñanza e investigación. Apuntes Metodológicos dirigida por Josse de Dock, Salamanca, Universidad de Salamanca, 1999. 
embargo, como todo corpus abierto, siempre cabe la posibilidad de ser ampliado posteriormente. En este periodo de ocho años, sin aparentes cambios políticos trascendentes y con la constante de Fraga Iribarne a la cabeza del Ministerio de Información y Turismo, destaca el hecho de que la narrativa traducida del inglés está en constante aumento. En cuanto al número de obras recogidas en el Catálogo TRACEni (1962-1969), en los primeros años de nuestro periodo, de 1962-1965, la media anual de novelas traducidas del inglés al español es de 1136, aunque este dato oscila entre las 700 y las 1500 obras por año. Hay que puntualizar que este volumen podría haber ascendido entre 19641966, de haber contado con los datos de las obras publicadas de la Bibliografía Española, datos que no tenemos debido a que en este periodo estos anuales no se publicaron. Desde 1964 hasta 1967 apreciamos un incipiente crecimiento anual en la publicación de obras traducidas del inglés, especialmente en 1966 y 1967, coincidiendo con la publicación de la Ley de Prensa de 1966 (BOE 19-III-66). Sin duda alguna, este aumento está directamente relacionado con la política exterior aperturista y con el intento, por parte del gobierno, de lavado de imagen de cara al exterior. Este progresivo incremento de la narrativa importada en estos años nos lleva a pensar que la promulgación y aplicación de la Ley de Prensa de 1966, aparentemente más liberal que la anterior y, dentro del mandato de Manuel Fraga Iribarne, pudo tener incidencias en el aumento de la publicación de obras. Sin embargo, de nuevo en 1968 apreciamos un pequeño receso en el volumen anual de obras. Este descenso se agrava en 1969, año de cambios políticos en el Gabinete de Franco con la sustitución como Ministro de Información y Turismo de Manuel Fraga Iribarne por Sánchez Bella (1969-73). Siempre que hay cambio de gobierno varios aspectos de la vida del país se ven afectados, y no fue menos el terreno cultural. Si además del cambio de gobierno, tenemos en cuenta que entra un ministro más conservador que el 
anterior, no es de extrañar que este hecho fuese uno de los motivos por el que el número de obras pudiera haberse visto reducido de un modo notable. Observamos, de este modo, que aparte de los cambios que introdujo la nueva Ley, el aumento o disminución de publicaciones anuales está estrechamente vinculado al cambio de ministros en la cartera de Información y Turismo, y a su ideología más o menos aperturista. Puede que sea la causa de que en 1962, cuando entra Fraga en este Ministerio, comienza a subir el porcentaje de publicaciones de narrativa importada y traducida en España y, en 1969, cuando es sustituido por Sánchez Bella, político más conservador, las cifras vuelven a descender.

Los resultados acerca de los autores más traducidos del Catálogo no son sorprendentes, sino que se corresponden con los autores de más renombre o considerados canónicos según varias antologías ${ }^{20}$. La lista incluye nombres tan conocidos como Agatha Christie, Oscar Wilde, Erle Gardner Stanley, Pearl S. Buck, Zane Grey, Edgar Alan Poe, Charles Dickens, Frank Gill Slauhgter, Morris West o Frank Yerby. La lista comienza con la autora con más novelas publicadas, en este caso Agatha May Clarissa Millar, más conocida por su pseudónimo Agatha Christie.

En cuanto a las nacionalidades de los autores, debemos puntualizar que siempre hemos contabilizado que la lengua de las obras que se han publicado durante nuestro periodo sea el inglés, sin importar la nacionalidad de los autores origen. Así, en ocasiones aparecen autores de otras nacionalidades que en un principio no interesarían en nuestro estudio, pero que sí son relevantes por haber realizado su producción literaria en lengua inglesa. Con respecto a los países de narrativa importada en España entre 1962-1969, hay un total

\footnotetext{
${ }^{20}$ C. García Gual, «Sobre el canon de los clásicos antiguos», Ínsula, 600, (1996), pp. 5-7; H. Bloom et al., El canon literario, Madrid, Arco/Libros, 1998.
} 
predominio de la narrativa importada norteamericana, suponemos que en parte por la tendencia y el deseo de mantener y desarrollar lazos culturales y económicos ya existentes con dicho país. En cuanto a la nacionalidad de los autores, un $51 \%$ de los autores son norteamericanos frente al $26 \%$, casi la mitad, de británicos. El porcentaje restante corresponde a autores con nacionalidades diversas como canadiense, australiana, etc. Sin embargo, hemos querido establecer la distinción entre el número de autores y el número de sus obras dependiendo de la nacionalidad de sus autores, puesto que pudiera darse el caso de ser menos autores británicos que norteamericanos, como al final se ha comprobado, pero contar entre todos los autores británicos con mayor volumen de publicación que los norteamericanos. Este no ha sido finalmente el caso y siguen siendo las obras de autores norteamericanos, al igual que el número de autores de esta nacionalidad, las más numerosas en nuestro Catálogo, con un 55\%. Lo que sí hemos percibido es que las obras británicas ascienden un 10\% con respecto al número de autores británicos. Las cifras pasan de representar el $26 \%$ en cuanto a la nacionalidad de autores británicos hasta ocupar el 36\% del total de obras escritas por autores británicos, lo que viene a significar que de entre todos los autores británicos se han importado proporcionalmente más obras que de los autores norteamericanos.

Un aspecto a destacar que hemos constatado con respecto a la nacionalidad de las obras, ha sido la existencia de textos procedentes de otros países miembros de la Commonwealth como Australia, Nueva Zelanda, Canadá o Sudáfrica. Aunque su narrativa es minoritaria, hay una clara tendencia a establecer contactos culturales con autores procedentes de culturas más desconocidas para la cultura meta.

Con respecto a los autores meta o traductores, del total de 9118 obras, sólo contamos con un número de 4846 obras de las cuales sabemos el traductor. 
Han sido muy pocos traductores los que han superado un número de obras mayor a 100. Observando los nombres de los que más han traducido indicamos que son muchos los que no se han especializado en un género concreto, sino que la mayoría de ellos han traducido a varios autores y diferentes tipos de obras, aunque siempre con excepciones. Concluimos que la selección de los traductores y de las obras que se traducen y se publican puede ser una cuestión editorial más que personal. Si la editorial prefiere conseguir coherencia y continuidad en la traducción de las obras de un mismo autor, lo más probable es que las encargue a un mismo traductor, por el contrario, si lo que prima mayoritariamente es la rapidez de las traducciones, las editoriales normalmente prefieren encargar las obras a traductores diferentes.

Con relación a los títulos de las novelas más traducidas, no podemos asegurar con exactitud qué tipo de novela era la más preferida por los lectores españoles, puesto que de entre las novelas más traducidas hay varias pertenecientes a géneros literarios distintos, como puede ser el detectivesco (Aventuras de Sherlock Holmes), el de aventuras (La Isla del Tesoro, Robinson Crusoe), la novela religiosa (Fabiola), etc. Sin embargo, hay un hecho notorio con relación a las novelas más traducidas, y es que varios de los autores de estas novelas se encuentran también entre los autores más traducidos. Este hecho nos lleva a afirmar que las novelas más traducidas suelen pertenecer a autores considerados clásicos o canónicos, muy conocidos tanto en el contexto emisor como en el receptor, quedando en una posición más marginal aquellos autores de menos renombre.

El fenómeno de la pseudotraducción ${ }^{21}$, que ya había comenzado en los años 50, continúa en la década que nos atañe. Esto puede ser una consecuencia

\footnotetext{
${ }^{21}$ Ver con más detalle Toury (1995), Rabadán (2000b) y Santoyo (1984) incluidos en la Bibliografía final.
} 
de la masiva importación de la narrativa anglosajona, por medio de la cual se incorporan rasgos estilísticos propiamente ingleses o norteamericanos, títulos de novelas, nombres propios de personajes, etc. Toda esta tendencia desencadena la creación de un género nuevo en la cultura meta, como es el detectivesco, que en principio no pertenecía a la cultura española. Este género importado dejó una influencia notoria en el panorama literario español. Nos podemos preguntar cuáles eran las razones por las cuales se importaba este género. Algunas causas podrían haber sido las siguientes: por motivos comerciales de las editoriales, por ser un camuflaje para la propagación de ideas contrarias al régimen, o simplemente por la popularidad que alcanzó entre los lectores de nuestro país.

Con respecto a los datos sobre las editoriales y el lugar de publicación de las obras, otro de los logros sobresalientes de este análisis estadístico es que se confirma nuevamente la tendencia de que son las editoriales situadas en Barcelona las que publican mayoritariamente las obras importadas, con un $84 \%$, frente a una minoría del 15\% que lo hacen en Madrid y un 1\% que se distribuye por el resto de la geografía del páis. En toda esta década surgen muchas editoriales que tienden a abrirse paso en los mercados, también debido a la cláusula de la Ley de 1966 por la que se suprimía la censura previa (BOE 19-III66). Eran en muchos casos los editores los que se atrevían a aplicar sus propios criterios de censura y se arriesgaban a llevar adelante la publicación de una obra mediante la consulta voluntaria. Las cinco editoriales con mayor volumen de publicación del Catálogo son Plaza y Janés, que con 1136 obras encabeza la lista, seguida de Molino (997) 22, Bruguera (845), Toray (671) y Planeta (647). Además, en nuestro Catálogo contamos con la cifra de 186 editoriales diferentes

\footnotetext{
${ }^{22}$ La cifra entre paréntesis se refiere al número de obras publicadas por editorial y recogidas en el Corpus 0/ Catálogo.
} 
y, después de lo señalado hasta ahora, se corrobora la hipótesis previa de que son las editoriales españolas situadas en Barcelona las que publican la mayor parte de la narrativa consumida entre 1962-1969, sin quitar el mérito a la madrileña Aguilar, que ha publicado 625 de obras las obras de nuestro Catálogo.

Otro dato significativo del análisis estadístico nos lo ha proporcionado la extensión de las obras, fenómeno que está íntimamente relacionado con las colecciones en las que el libro se editó. La cantidad de páginas de un libro a veces refleja decisiones de una editorial. Por eso, en muchas ocasiones, las colecciones, guiadas por el criterio de homogeneización, tienen un número fijo de páginas. Sería interesante averiguar en al análisis descriptivo-comparativo si la obra original poseía más o menos el mismo número de páginas que la obra traducida, o por el contrario, si este número se vio modificado significativamente. En el caso de que este hecho ocurriera, habría que comprobar si la decisión fue tomada por el traductor (autocensura), si se debió al condicionamiento externo de la censura oficial, o si tuvo que ver con una decisión particular de la editorial. A su vez, el análisis de la extensión y el precio de las colecciones más importantes del Catálogo nos ha proporcionado datos interesantes acerca de la accesibilidad del público lector a cada colección y acerca del concepto de literatura de prestigio o popular. Primeramente, la extensión de un libro repercute directamente en el precio final y su coste de un libro está en función de los pliegos que se hayan necesitado para su elaboración. La extensión del libro está estrechamente vinculada al precio final, ya que el coste incrementa en función del número de pliegos empleados en la creación del libro. En muchos casos las colecciones más extensas van asociadas con la idea de prestigio o de literatura tradicional. Por el contrario, puede que los libros más pequeños tengan una difusión más masiva, ya que su coste es más 
reducido, pero puede que su consideración literaria se acerque más a la idea de literatura popular o subliteratura.

Pero sin duda, uno de los logros más sobresalientes del análisis estadístico de los datos ha sido la observación de la clasificación censora sobre cada obra. Dentro de los varios tipos de calificaciones (obras autorizadas, anuladas, denegadas, con oficio, con silencio administrativo, sin resolver, suspendidas o con tachaduras), las obras autorizadas suponen un $89 \%$ del total, lo cual quiere decir que la gran mayoría de las obras publicadas durante nuestro periodo fueron autorizadas sin mayor problema por la comisión de censura. A pesar de esta cifra tan elevada, un grupo textual homogéneo en el que sí estamos muy interesados es el compuesto por las obras anuladas (1), suspendidas (3), denegadas (72) y con tachaduras (278). Todas estas obras sí que supusieron problemas a la comisión de censura, quizá por contener una temática problemática en lo referente a cuestiones morales, religiosas o acerca del régimen.

\section{[3. Construcción de los futuros Corpus 1 y 2 TRACEni (1962-1969)]}

Nuestro objetivo de ahora en adelante es la construcción de un Corpus 1 paralelo representativo de textos escritos en inglés y sus correspondientes traducciones al castellano. Las características principales de dicho Corpus 1 TRACEni (1962-1969) serán las mismas que las establecidas para el Corpus 0 incluyendo otro nuevo criterio. Finalmente, y fijándonos en el último resultado relevante del análisis cuantitativo y cualitativo del Corpus 0 acerca del criterio de la calificación censora, creemos que éste va a ser determinante para la elección de nuestros textos. No podemos olvidar nuestro interés sobre los textos narrativos traducidos y afectados por la (auto)censura. Por eso, en principio, 
Metodología para la narrativa de traducciones censuradas inglés-español...

estamos interesados en aquéllas obras que han sido modificadas con tachaduras, denegadas, anuladas, etc., por parte de la comisión de censura. En último término, nuestra elección de los conjuntos textuales dependerá también de la disponibilidad del material y no de otro tipo de preferencias.

Una vez se haya compilado el Corpus paralelo 1, el siguiente paso que se dibuja en el horizonte será la construcción del Corpus 2 y el correspondiente diseño de un modelo de análisis descriptivo-comparativo de los textos meta (TM) y sus respectivos originales (TO) que en él se hayan incluido. Por medio del análisis macrotextual y microtextual de los textos de este Corpus $2^{23}$, una vez que se hayan descrito los datos y explicado los comportamientos traductores, podremos llegar al establecimiento de una serie de regularidades que, siguiendo un patrón recurrente, se aceptarán como normas de comportamiento traductor de ese periodo en concreto. Sólo habiendo seguido los pasos previos aquí indicados, y habiendo observado detenidamente la reincidencia de las normas escogidas por el traductor, será posible llegar a la formulación de leyes refutables que corroboren los datos. Es precisamente la formulación de dichas leyes lo que se encuentra "más allá" de los EDT, según Toury. De esta manera, se podrá comprobar si la autocensura se convirtió en la práctica más frecuente utilizada por los traductores de la época o, en caso contrario, cuál fue la norma operacional por excelencia que rigió la traducción de textos narrativos en la España de los años sesenta.

${ }^{23}$ M. Tymozcko, «Connecting The Two Infinite Orders. Research Methods In Translation Studies», en T. Hermans (Ed), Crosscultural Transgressions. Research Models in Translation Studies II. Historical and Ideological Issues, Manchester, St. Jerome Publishing, 2002, pp. 9-25. 


\section{BIBLIOGRAFÍA}

ALVSTAD, C., La traducción como mediación editorial. Un estudio de 150 libros para niños y jóvenes publicados en Argentina durante 1997, Doktorsavhandling, Göteborgs Universitet, 2003.

BLOOM, H. et al., El canon literario, Madrid, Arco/Libros, 1998.

CARAVEDO, R., Lingüística del Corpus. Cuestiones teórico-metodológicas aplicadas al español. Colección Gramática Española. Enseñanza e investigación. Apuntes Metodológicos dirigida por Josse de Dock, Salamanca, Universidad de Salamanca, 1999.

CHAMOSA, J. L., (ed) Proceedings of the 23rd Internacional Conference of AEDEAN, León, Universidad de León, 2003. (Versión en CD-ROM).

GARCÍA GUAL, C., «Sobre el canon de los clásicos antiguos», Ínsula, 600, (1996), pp. 5-7.

GENETTE, E., Paratexts. Thresholds of interpretation, Cambridge, CUP. Traducción de Jane E. Lewin del original francés de 1987: Paratextes, Paris:, Senil, 1997.

GÓMEZ CASTRO, C., Traducción y narrativa censurada inglés-español (1970-1978): análisis del corpus 0 TRACEni,. León, Universidad de León. Memoria de Licenciatura inédita, 2004.

GUTIÉRREZ LANZA, C., Traducción y censura de textos cinematográficos en la España de Franco: Doblaje y subtitulado inglés-español (1951-1975), León, Servicio de Publicaciones, Universidad de León, 2000a.

GUTIÉRREZ LANZA, C., 2004b. «Herramientas de investigación de EDTAV: la Ficha y el Catálogo TRACEc», en Ortega Arjonilla, E. (dir), Panorama actual de la investigación en Traducción e Interpretación. Vol III, Granada: Atrio, 447455.

GUTIÉRREZ LANZA, C., 2005. «La labor del equipo TRACE: metodología descriptiva de la censura en traducción», en Merino, R.; J.M. Santamaría \& E. Pajares (eds), Trasvases Culturales: Literatura, Cine y Traducción 4, Vitoria, Servicio Editorial de la Universidad del País Vasco, pp. 55-64. ISBN: 848373-707-8.

HERMANS, T. (ed), Crosscultural Transgressions. Research Models in Translation Studies II. Historical and Ideological Issues, Manchester, St. Jerome, 2002.

HOLMES, J. S., Translated! Essays on Papers on Translation Studies, Amsterdam, Rodopi, 1988a.

HOLMES, J. S., «The Name and Nature of Translation Studies», en J.S. Holmes,1988a, pp. 67-80. 1988b. 
MERINO, R., Traducción, Tradición y manipulación. Teatro inglés en España 19501990, León, Universidad de León y Lejona, Universidad del País Vasco, 1994.

PÉREZ ÁlVAREZ, I., Aproximación descriptiva al catálogo de traducciones de narrativa inglés-español TRACEni (1958-1962). Estudio preliminar, León, Departamento de Filología Moderna, Universidad de León. Memoria de Licenciatura inédita. 2002.

PÉREZ DE HEREDIA, M., «La traducción de obras dramáticas en lengua inglesa en los escenarios públicos españoles de posguerra», en Chamosa, J.L. (ed), pp. 1-6., 2003. (Versión en CD-ROM).

RABADÁN, R., Equivalencia y traducción, León, Universidad de León, 1991.

RABADÁN, R., (ed). Traducción y censura inglés-español: 1939-1985. Estudio Preliminar, León, Universidad de León, ULE, 2000a.

RABADÁN, R., «Modelos importados, modelos adaptados: pseudotraducciones de narrativa popular inglés-español. 1955-1981», en Rabadán, Rosa (ed), 2000a, pp. 256-277, 2000b.

RIOJA BARROCAL, M., Traducción y censura de textos narrativos inglés-español (1962-1969): Delimitación contextual y propuesta de catalogación TRACEni (1962-1969), León, Departamento de Filología Moderna, Universidad de León. Trabajo de investigación inédito, 2003.

RIOJA BARROCAL, M., Traducción inglés-español y censura de textos narrativos: Construcción y Análisis del Corpus O TRACEni (1962-1969), León, Universidad de León. Memoria de Licenciatura inédita, 2004.

SANTOYO MEDIAVILLA, J., "La traducción como técnica narrativa», en Actas del IV Congreso de AEDEAN, Salamanca, Universidad de Salamanca, 1984, pp. 37-53.

SERRANO FERNÁNDEZ, L., Traducción y censuras de textos cinematográficos inglés-español 1970-1985, León, Departamento de Filología Moderna, Universidad de León. Tesis doctoral inédita, 2003.

SINOVA, J., La censura de Prensa durante el franquismo (1936-1951), Madrid, Espasa Calpe, 1989.

TOMÁS ZAMARRIEGO, S. J., Enciclopedia de orientación bibliográfica, Vol. I-IV, Barcelona, Juan Flors, 1965.

TOURY, G., «What Lies Beyond Descriptive Translation Studies? », en M.A. Vega \& R. Martin-Gaitero (eds.), La palabra vertida. Investigaciones en torno a la traducción. Actas de los VI Encuentros Complutenses en torno a la traducción, Madrid, Editorial Complutense, 1997, pp. 69-80. [Versión en español en http://www.tau.ac.il/ toury/]

TOURY, G., «The Nature and Role of Norms in Literary Translation», en G. Toury, 1980, pp. 51-62, 1978. 
TOURY, G., Descriptive Translation Studies and Beyond, Amsterdam/Philadelphia, John Benjamins, 1995.

TYMOCZKO, M., «Connecting The Two Infinite Orders. Research Methods In Translation Studies», en T. Hermans (Ed), Crosscultural Transgressions. Research Models in Translation Studies II. Historical and Ideological Issues, Manchester, St. Jerome Publishing, 2002, pp. 9-25. 